\title{
Accelerated Neutrophil Apoptosis in the Acquired Immunodeficiency Syndrome
}

\author{
David L. Pitrak, ${ }^{\star}$ Ho Chie Tsai, ${ }^{*}$ Kathleen M. Mullane, ${ }^{*}$ Sarah H. Sutton, ${ }^{*}$ and Paul Stevens ${ }^{\star}$ \\ *Department of Medicine, University of Illinois College of Medicine at Chicago, West Side VA Medical Center, Chicago, Illinois 60612; \\ and ${ }^{\ddagger}$ Amgen, Inc., Thousand Oaks, California
}

\begin{abstract}
Neutrophil (PMNL) function defects occur as a consequence of HIV infection. This study examined PMNL apoptosis in patients with the acquired immunodeficiency syndrome (AIDS) to determine if accelerated apoptosis contributes to impaired function.

PMNL were isolated from $10 \mathrm{HIV}$-infected patients with CD4+ lymphocyte counts $<200 / \mathrm{mm}^{3}$ without signs of active infection and 7 healthy volunteers. PMNL were stained with acridine orange and ethidium bromide after $0,3,6$, and $18 \mathrm{~h}$ in culture, and examined for the morphologic changes of apoptosis and viability by fluorescent microscopy. Apoptosis was also demonstrated by electron microscopy, flow cytometry, and DNA gel electrophoresis.

Apoptosis was minimal at $0 \mathrm{~h}$, but PMNL from AIDS patients exhibited significantly greater apoptosis than controls at $3 \mathrm{~h}(22.5 \pm 11.5$ vs. $8.9 \pm 6.9 \%, P=0.015), 6 \mathrm{~h}(38.1 \pm 14.2$ vs. $18.1 \pm 4.5 \%, P=0.003)$, and $18 \mathrm{~h}(71.3 \pm 19.0$ vs. $38.8 \pm$ $16.7 \%, P=0.002)$. Viabilities were $\geq 88.0 \%$ for both groups from $0-6 \mathrm{~h}$, but by $18 \mathrm{~h}$ viability was significantly decreased for the HIV group $(58.8 \pm 12.4$ vs. $83.5 \pm 10.4 \%, P=0.001)$ due to an increase in non-viable apoptotic cells. Incubation with serum from AIDS patients had no effect on control PMNL, and incubation with control serum did not reduce the rate of apoptosis of PMNL from AIDS patients. Incubation with granulocyte colony-stimulating factor (G-CSF) in vitro significantly decreased apoptosis for PMNL from AIDS patients.

PMNL from patients with AIDS exhibit markedly accelerated apoptosis ex vivo. In vivo, apoptosis and functional impairment of PMNL may contribute to the risk of secondary infections, and cytokine therapy may be of potential clinical benefit in this circumstance. (J. Clin. Invest. 1996. 98:2714-2719.) Key words: cell death - cytokines • DNA • granulocyte colony-stimulating factor $\cdot$ HIV
\end{abstract}

\section{Introduction}

Apoptosis is one of the two major mechanisms for cell death. It can be distinguished from the other major mechanism of cell death, necrosis, morphologically (apoptosis is characterized by cell shrinkage and nuclear pyknosis, but no membrane rupture or inflammatory reaction), as well as by demonstrating the

Address correspondence to David Pitrak, Department of Medicine, Section of Infectious Diseases, University of Illinois, Room 913 CSB, M/C, 808 S. Wood St., Chicago, IL. Phone: 312-666-6500 ext. 3457; FAX: 312-455-5893.

Received for publication 24 June 1996 and accepted in revised form 9 October 1996.

The Journal of Clinical Investigation

Volume 98, Number 12, December 1996, 2714-2719 characteristic DNA fragmentation $(1,2)$. Neutrophils (PMNL) ${ }^{1}$ have the shortest half-life of all circulating leukocytes, and on leaving the bone marrow are programmed to die within $\sim 24 \mathrm{~h}$. Aging PMNL spontaneously undergo apoptosis and are recognized and phagocytosed by monocytes and macrophages (3). This is a normal mechanism of clearance of PMNL from a site of infection which prevents further tissue injury (4). PMNL activation by circulating bacterial products, endogenous cytokines, and other pro-inflammatory mediators may affect the rate of PMNL apoptosis (5-9).

PMNL function is impaired in the later stages of HIV infection, and this abnormal function may predispose patients to secondary bacterial infections and/or certain opportunistic infections (10-14). Because apoptotic PMNL are functionally impaired (15), we hypothesized that the abnormalities of PMNL function observed in HIV infection might be the result of accelerated apoptosis. Apoptosis is proposed to be one mechanism causing loss of function and depletion of numbers of CD4+ lymphocytes in HIV infection, and accelerated B cell apoptosis has also been described in these patients $(16,17)$. To date, however, there have been no studies of PMNL apoptosis in HIV infection.

The purpose of this study was to examine PMNL apoptosis ex vivo in a group of patients with AIDS and compare the rate of apoptosis to that of PMNL from controls. Our data show that the rate of PMNL apoptosis is accelerated in AIDS. The defect is intrinsic and not an effect of a serum factor. This defect is reversible with granulocyte colony-stimulating factor (G-CSF), a cytokine known to decelerate apoptosis and prolong PMNL survival.

\section{Methods}

Subjects. $10 \mathrm{HIV}$-infected patients with CD4+ lymphocyte counts $<200 / \mathrm{mm}^{3}$ without fever or other symptoms or signs of active secondary infections were enrolled, and 7 healthy volunteers without HIV risk factors served as controls. Samples from patients and volunteers were tested in parallel. Specimens from selected volunteers were run on several days to determine the day to day variation of the assay, but only day one results were used for comparison to AIDS patients.

PMNL isolation, culture. Heparinized blood was collected and PMNL were isolated by a standard method of density-gradient centrifugation over Ficoll-Hypaque (Histopaque 1077; Sigma Chemical Co., St. Louis, MO), sedimentation in $10 \%$ dextran (Sigma), and lysis of the remaining red blood cells with $\mathrm{NH}_{4} \mathrm{Cl}$ buffer, $\mathrm{pH} 7.4$ (18). PMNL isolated by this procedure were $\geq 95 \%$ pure and $\geq 95 \%$ viable by trypan blue exclusion. PMNL were washed and resuspended at a concentration of $10^{7}$ cells $/ \mathrm{ml}$ in RPMI 1640 media with L-glutamine

1. Abbreviations used in this paper: $\mathrm{G}-\mathrm{CSF}$, granulocyte colony-stimulating factor; NVA, non-viable, apoptotic; NVNA, non-viable, nonapoptotic; PMNL, neutrophil; VA, viable, apoptotic; VNA, viable, non-apoptotic. 
(BioWhitaker, Walkersville, MD), 10\% fetal calf serum (HyClone Laboratories, Logan, UT), and penicillin and streptomycin (Sigma). Cell cultures were incubated at $37^{\circ} \mathrm{C}$ in $5 \% \mathrm{CO}_{2}$. Aliquots were taken at $0,3,6$, and $18 \mathrm{~h}$ for apoptosis assays and hemocytometer cell counts.

In vitro effects of serum and $G-C S F$. The effect of serum on PMNL apoptosis was examined by incubating PMNL with $20-50 \%$ fresh serum collected from HIV-patients or controls. The effect of G-CSF (r-metHuG-CSF, filgrastim; Amgen, Inc., Thousand Oaks, CA) was examined by incubating PMNL with $50 \mu \mathrm{g} / \mathrm{ml}(5,000 \mathrm{U} / \mathrm{ml}$, specific activity of r-metHuG-CSF $1.0 \pm 0.6 \times 10^{8}$ units $/ \mathrm{mg}$ protein). Sufficient numbers of PMNL were not available for all subjects to conduct these experiments.

Fluorescent microscopy. Apoptosis was studied morphologically using fluorescent dyes that intercalate DNA (19). Acridine orange stains DNA bright green, allowing visualization of the nuclear chromatin pattern. Apoptotic cells have condensed chromatin that is uniformly stained. Ethidium bromide stains DNA orange, but is excluded by viable cells. Dual staining allows enumeration of four populations: $(a)$ viable, non-apoptotic (VNA), $(b)$ non-viable, nonapoptotic (NVNA), $(c)$ viable, apoptotic (VA), and $(d)$ non-viable, apoptotic (NVA). PMNL $(25 \mu \mathrm{l})$ were stained with $2 \mu \mathrm{l}$ of acridine orange $(100 \mu \mathrm{g} / \mathrm{ml}$; Remel, Lenexa, KS) and $2 \mu \mathrm{l}$ of ethidium bromide (100 $\mu \mathrm{g} / \mathrm{ml}$; Sigma) and then examined by fluorescent microscopy with a fluorescein filter set. One microscopist was blinded to the status of PMNL donor. The results of the blinded microscopist were compared to the results of a second microscopist who was blinded to the results obtained by the first reader, but not patient status, in order to determine interreader variability.

The percentage of apoptotic and non-viable PMNL were calculated as follows:

$$
\begin{aligned}
& \% \text { Apoptosis }=\frac{\text { VA + NVA }}{\text { Total cell count }(\text { VNA + NVNA + VA + NVA })} \\
& \% \text { Non-Viable }=\frac{\text { NVNA }+ \text { NVA }}{\text { Total cell count }} .
\end{aligned}
$$

Light microscopy, transmission electron microscopy. The morphological changes of apoptosis were also demonstrated by light microscopic examination of Wright-stained cytospins and by transmission electron microscopy of cytocentrifuged samples fixed with $1 \%$ glutaraldehyde in PBS.

Flow cytometry. PMNL were stained with $0.1 \%$ propidium iodide (Coulter Immunology, Hialeah, FL) for $30 \mathrm{~min}$ at room temperature, washed with PBS with $0.1 \%$ sodium azide, and fixed with $1 \%$ paraformaldehyde. A minimum of $10^{6} \mathrm{PMNL}$ were analyzed by a FACScan ${ }^{\circledR}$ flow cytometer (21). The percent apoptotic cells was determined by light microscopy with Wright-stained cytospins and by gating on the PMNL population with decreased fluorescence to the left of the major cell peak on the DNA histogram.

DNA fragmentation. DNA was isolated from $10^{7} \mathrm{PMNL}$ at various time points by modification of methods used for assessment of DNA fragmentation in thymocytes (21). In brief, the cells were lysed with TES buffer (20 mM Tris $\mathrm{HCl}, 200 \mathrm{mM}$ EDTA, and 1\% SDS) with RNase $(20 \mu \mathrm{g} / \mathrm{ml}$; Boehringer Mannheim, Indianapolis, IN) at $37^{\circ} \mathrm{C}$ for $1 \mathrm{~h}$. Proteins were denatured by incubation with proteinase $\mathrm{K}\left(1 \mathrm{mg} / \mathrm{ml}\right.$; Boehringer Mannheim) at $55^{\circ} \mathrm{C}$ for $3 \mathrm{~h}$. The denatured protein was removed by phenol extraction. The DNA was then precipitated with alcohol overnight at $-20^{\circ} \mathrm{C}$. The next day the DNA was rinsed with alcohol, mixed with loading buffer, and then electrophoresed in a $2 \%$ agarose gel containing $10 \mu \mathrm{g} / \mathrm{ml}$ ethidium bromide. The gel was examined and photographed under UV light to look for evidence of regular DNA fragmentation pattern (laddering) characteristic of apoptosis.

Statistical analysis. Results are expressed as the mean \pm standard deviation. Interreader variability was analyzed by ANOVA. Means of groups were analyzed by the two-tailed Student's $t$ test. The effects of serum and G-CSF were analyzed by paired $t$ test. Statistical significance was defined as $P<0.05$.

\section{Results}

The morphological changes of apoptosis were easily observed transmission electron microscopy of PMNL taken from cultures over time (Fig. 1). The cells undergoing apoptosis show progressive cytoplasmic shrinkage and nuclear condensation. The nuclear chromatin stains uniformly rather than having heterogenous staining due to the normal distribution of euchromatin and heterochromatin. At $0 \mathrm{~h}$, neither the PMNL from HIV patients nor those from controls showed morphological evidence of apoptosis. The number of apoptotic PMNL steadily increased for patient and control PMNL, but the rate of apoptosis was much more rapid for patient PMNL than controls. By $18 \mathrm{~h}$ a much larger proportion of the PMNL from the HIV patients were apoptotic as compared to controls.

Quantitative assessment by fluorescent microscopy confirmed the results of light and electron microscopy and allowed for simultaneous assessment of viability (see Fig. 2). Apoptosis was minimal at $0 \mathrm{~h}$, but PMNL from AIDS patients exhibited significantly increased apoptosis at $3 \mathrm{~h}(22.5 \pm 11.5$ vs. $8.9 \pm$ $6.9 \%, P=0.015), 6$ h $(38.1 \pm 14.2$ vs. $18.1 \pm 4.5 \%, P=0.003)$, and $18 \mathrm{~h}(71.3 \pm 19.0$ vs. $38.8 \pm 16.7 \%, P=0.002)$. Viabilities were $\geq 88.0 \%$ for both groups from $0-6 \mathrm{~h}$, but by $18 \mathrm{~h}$ viability was significantly decreased for the HIV group (58.8 \pm 12.4 vs. $83.5 \pm 10.4 \%, P=0.001)$ because of the increased proportion of non-viable apoptotic cells. Total cell counts were also lower for the HIV PMNL cultures at $18 \mathrm{~h}\left(4.6 \pm 3.2 \times 10^{7} / \mathrm{ml}\right.$ vs. $\left.6.6 \pm 1.3 \times 10^{7} / \mathrm{ml}, P=0.15\right)$ indicating that some of the nonviable apoptotic PMNL had eventually lysed. This also means that the percent apoptosis for the HIV PMNL at $18 \mathrm{~h}$ is an underestimate since the non-viable apoptotic cells that had lysed were not counted and therefore were not included in the calculation. The absolute number of viable, non-apoptotic PMNL was decreased for the patients $\left(2.1 \pm 2.7 \times 10^{7} / \mathrm{ml}\right.$ vs. $3.8 \pm 1.8 \times$ $\left.10^{7} / \mathrm{ml}\right)$, although this did not reach statistical significance $(P=$ 0.21 ) because of the wide standard deviations for the total cell counts.

The fluorescent microscopic evaluation of apoptosis is reproducible and repeatable. One microscopist was blinded with regard to the status of the subject, patient or control. Another microscopist was not blinded to the status of the patient, but was blinded to the results from the first microscopist. There was excellent interreader agreement as to the percent apoptosis at all time points. ANOVA revealed that only $11.9 \%$ of the total variation in apoptosis at $18 \mathrm{~h}$ was due to different readers, while $88.1 \%$ was due to differences in the means for individual subjects. This indicates that the assay is very reproducible. Because patients were only assayed one time, it was not possible to determine the relative proportion of the total observed variation that was due to day to day variability in apoptosis. However, repeated measures for two selected controls showed little day to day variation (percentage of apoptosis at $18 \mathrm{~h}$, Control $1=26.6 \pm 5.8, n=13$; Control $2=22.6 \pm 7.6, n=8$ ). This suggests the apoptosis assay is repeatable as well as reproducible, although the day to day variation may be greater for the patients.

Although the morphological changes observed over time were clearly due to apoptosis, FACS ${ }^{\circledR}$ analysis after DNA staining and electrophoresis of DNA extracted from PMNL were performed to demonstrate DNA fragmentation, the hallmark of apoptosis. The results of FACS analysis after staining with propidium iodide, another fluorescent dye that interca- 

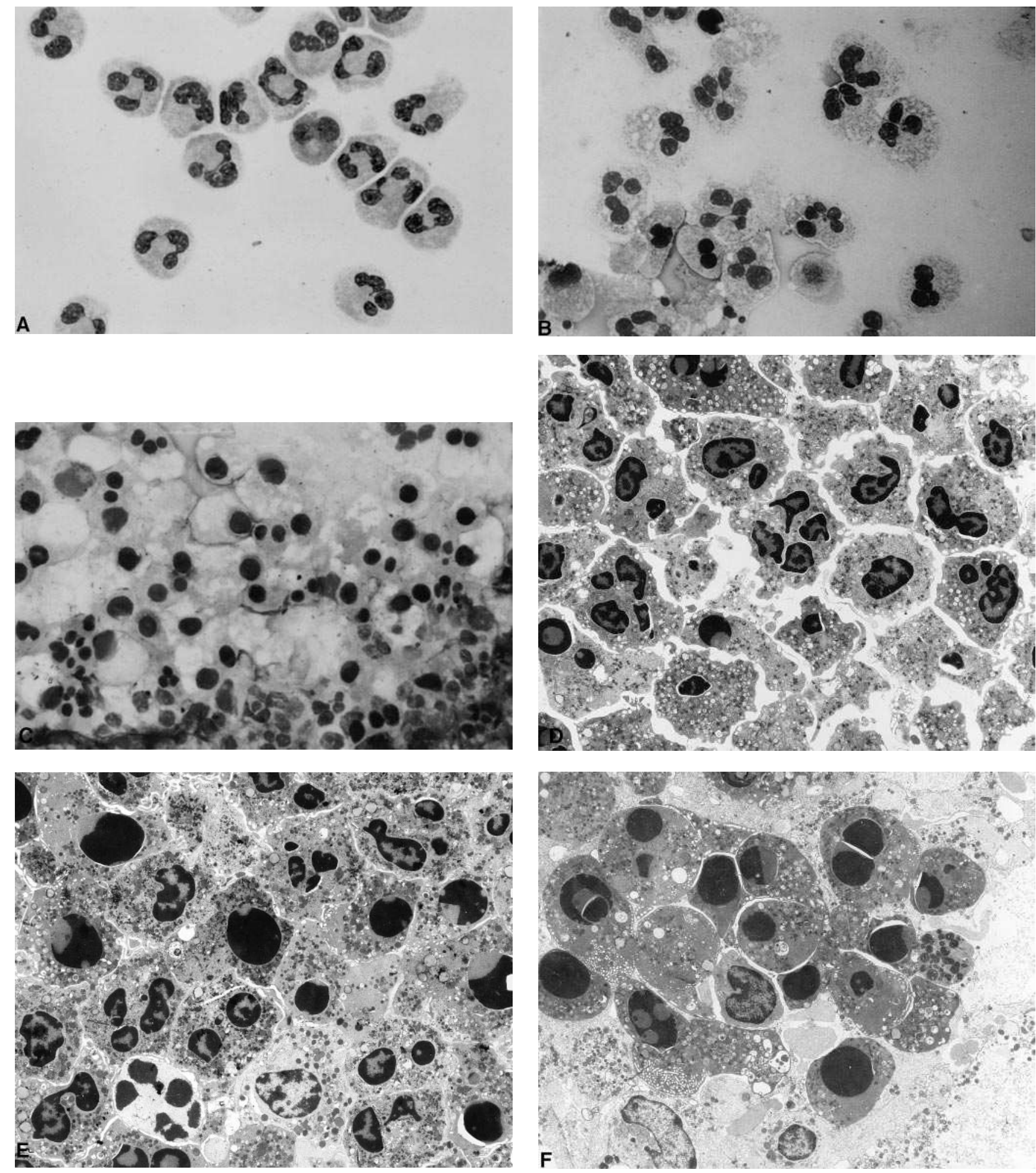

Figure 1. Morphological changes of neutrophil apoptosis. Cytospins of neutrophils in culture were Wright-stained and examined by light microscopy. (A) Neutrophils from a control subject at $0 \mathrm{~h}$ in culture with normal morphology. The neutrophils from AIDS patients also appeared normal at $0 \mathrm{~h}$. (B) Apoptotic cells with decreased cytoplasm and pyknotic nuclei can be identified at $18 \mathrm{~h}$ in culture for the control neutrophils. $(C)$ Almost all the neutrophils from a patient with advanced HIV infection are apoptotic by $18 \mathrm{~h}$. These same morphological changes are evident on transmission electron micrographs. $(D)$ Control neutrophils at $0 \mathrm{~h},(E)$ control neutrophils at $18 \mathrm{~h}$, and $(F)$ neutrophils from an AIDS patient at $18 \mathrm{~h}$.

lates DNA, supported the findings of fluorescent microscopy (see Fig. 3). The histograms show that a larger proportion of PMNL from AIDS patients after $6 \mathrm{~h}$ in culture have decreased fluorescence after staining with propidium iodide. The per- centage of apoptotic PMNL at $6 \mathrm{~h}$, the cell population exhibiting less fluorescence than the major cell population (cells to the left of the major peak, the M1 region), was similar to that determined morphologically by fluorescent microscopy. Elec- 

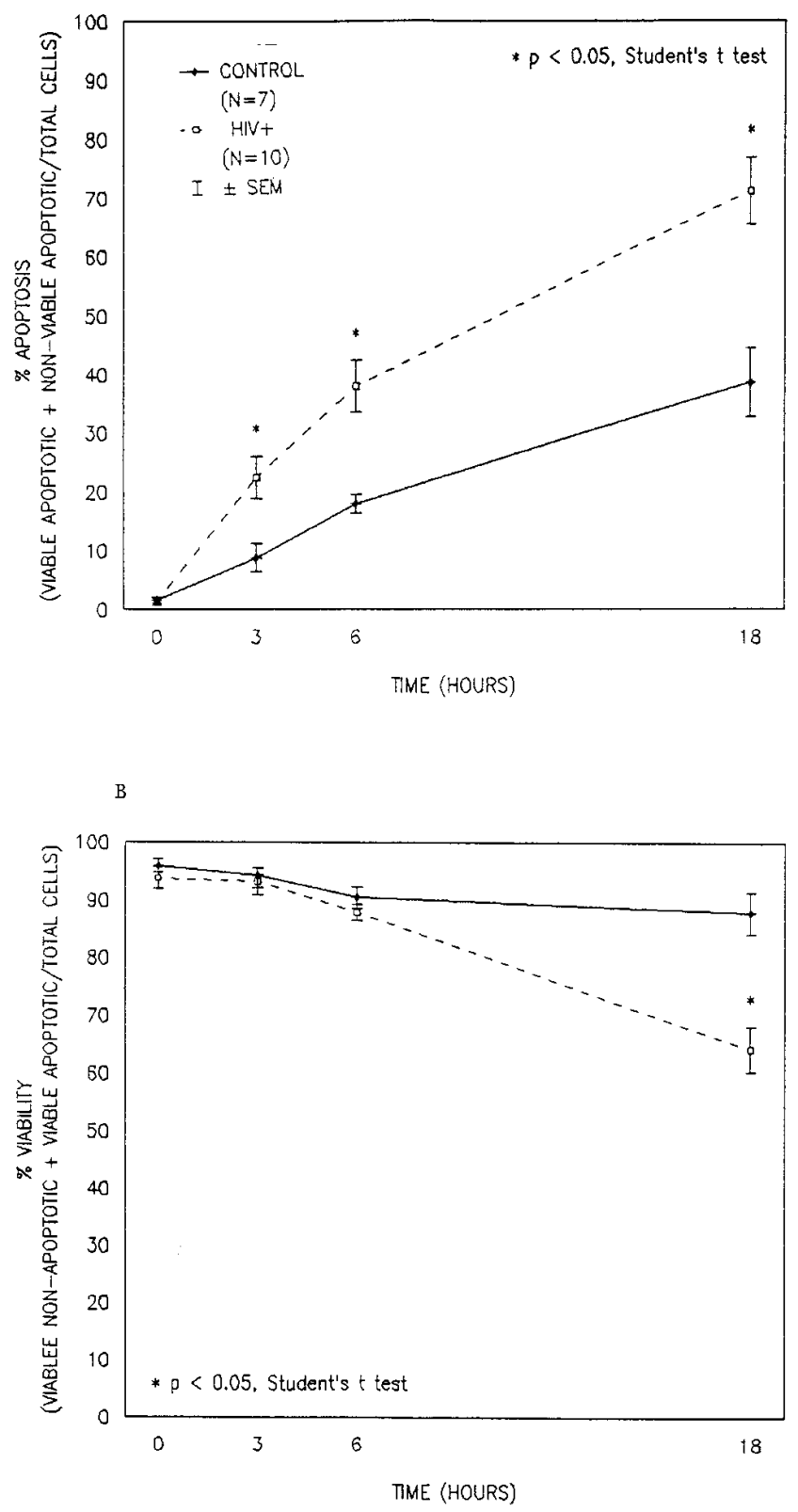

Figure 2. Apoptosis and viability of PMNL as assessed by fluorescent microscopy after staining with acridine orange and ethidium bromide. *Indicates a significant difference between the means of groups, $P<$ 0.05 , analyzed by Student's $t$ test. ( $A$ ) Apoptosis was significantly increased for PMNL from AIDS patients $(n=10)$ relative to control PMNL $(n=7)$ at 3,6 , and $18 \mathrm{~h}$. (B) Viability was significantly decreased for AIDS PMNL at $18 \mathrm{~h}$ due to an increase in the proportion of non-viable apoptotic cells.

trophoresis of DNA isolated from PMNL showed DNA fragmentation (laddering, bands at 200-bp intervals) characteristic of apoptosis at 6 and $18 \mathrm{~h}$, with PMNL from patients showing detectable DNA fragmentation earlier $(6 \mathrm{~h})$ than control PMNL (18 h, see Fig. 4).

We were unable to demonstrate any serum effect in vitro. Incubation with serum $(20-50 \%$ in different experiments) from AIDS patients whose PMNL showed rapid apoptosis did not significantly accelerate apoptosis in control PMNL. Con- versely, incubation with control sera had no effect on the rate of apoptosis for PMNL from the AIDS patients (data not shown). Accelerated apoptosis was partially reversible, however, by incubation with r-metHuG-CSF in vitro (Fig. 5). The mean difference in the rate of apoptosis for patient PMNL after $18 \mathrm{~h}$ was $-18.8 \pm 3.0 \%(P=0.001$, paired $t$ test $)$.

\section{Discussion}

Bacterial infections, not only opportunistic infections due to depressed cell-mediated immunity from progressive CD4+ lymphocyte depletion, occur with increased frequency and severity in HIV-infected patients (22-26). Infections with certain pathogens, such as Staphylococcus aureus and Pseudomonas aeruginosa, are often related to neutropenia and/or PMNL dysfunction, and these organisms are frequently involved in infections complicating the course of HIV infection. Several PMNL functions are impaired, including chemotaxis, phagocytosis, oxidative metabolism, and killing of bacterial and fungal pathogens (11-15). Killing of HIV-infected cells by PMNL through antibody-dependent cellular cytotoxicity is also defective in HIV infection $(27,28)$. There are no data of killing of free HIV by PMNL in AIDS, but studies with PMNL from controls have shown that PMNL can effectively kill HIV as long as the respiratory burst and generation of toxic oxygen species is intact (29). These studies suggest that abnormal PMNL function could contribute to the progression of HIV infection. Although there have been several studies documenting abnormal PMNL function in HIV infection, there is little information regarding the underlying mechanism(s).

Apoptosis is programmed cell death characterized by DNA fragmentation between nucleosomes due to endogenous endonuclease activation. Although many cells require some exogenous trigger to initiate apoptosis, PMNL are programmed to die within $24 \mathrm{~h}$ after release from the bone marrow (4). Several exogenous signals, however, can interfere with the genetic program for cell death, while other factors can accelerate the process (6-9). Apoptotic PMNL are functionally impaired (15). Consequently, accelerated PMNL apoptosis may at least in part account for the defects in PMNL function that occur in HIV infection. This is the first study demonstrating accelerated ex vivo PMNL apoptosis as a consequence of HIV infection. In fact, we are unaware of reports of any disease process in which apoptosis may contribute to the impairment of PMNL function associated with that particular condition, although accelerated apoptosis may not be unique to HIV infection.

The mechanism(s) by which PMNL apoptosis is accelerated as a consequence of HIV infection are not known. There are several other possible explanations. PMNL activation will accelerate the process of apoptosis, and data from our laboratory and others indicate that PMNL from HIV patients undergo in vivo activation, even in the absence of any secondary infection $(30,31)$. There are also a number of reports of changes in circulating cytokine levels in HIV infection (32). For example, levels of tumor necrosis factor-alpha (TNF- $\alpha$ ) are elevated in AIDS patients, and TNF- $\alpha$ is one of the cytokines known to accelerate PMNL apoptosis (5). Although cytokines and inflammatory mediators may contribute to the accelerated PMNL apoptosis in HIV infection, we were unable to demonstrate an effect of HIV-serum on apoptosis of control PMNL in vitro. This suggests that the accelerated apoptosis is 
A Control

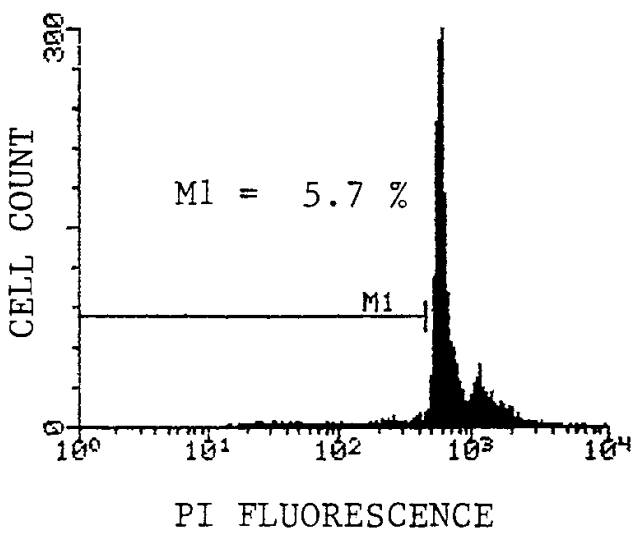

B Patient

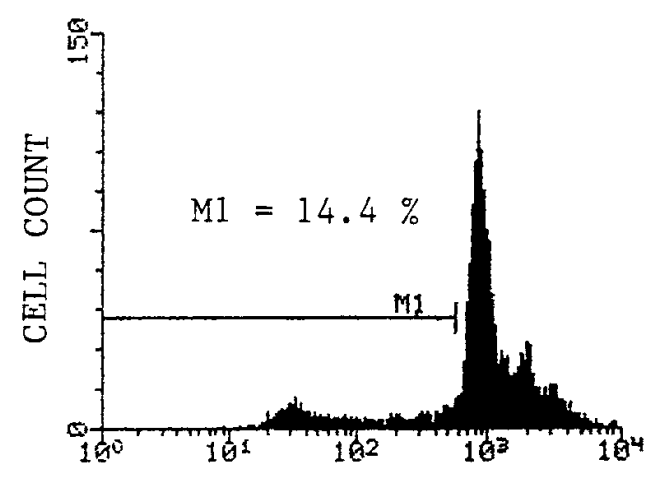

PI FLUORESCENCE
Figure 3. Apoptosis demonstrated by flow cytometry after staining with propidium iodide $(P I)$. DNA histograms were gated on forward light scatter and side light scatter to exclude clumps and debris. $(A)$ The proportion of apoptotic PMNL for a control after $6 \mathrm{~h}$ in culture, cells in the M1 region exhibiting decreased PI fluorescence, was much less than $(B)$ the proportion of apoptosis for PMNL from a patient with AIDS run in parallel at the same time point. The percent apoptosis determined by flow cytometry was the same as that determined by fluorescent microscopy. an intrinsic property of the PMNL in AIDS and is probably not due to exogenous circulating factors, although this cannot be excluded entirely. Finally, accelerated PMNL apoptosis may be due to the relative deficiencies of growth factors, colony-stimulating factors, and/or other cytokines. G-CSF and GM-CSF inhibit apoptosis and prolong PMNL survival (3335). There is evidence that G-CSF levels are abnormally low in HIV-infected patients as compared to other patients with similar degrees of relative neutropenia, and this may result in increased apoptosis $(36,37)$. The absence of growth factors has been shown to increase apoptosis in other cell types. Lympho-

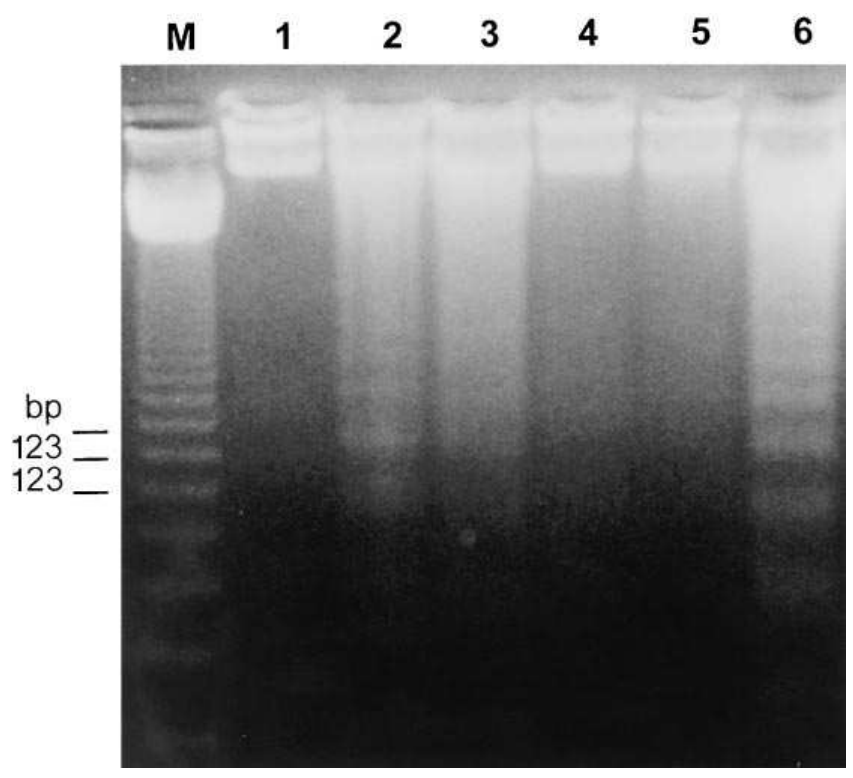

Figure 4. DNA fragmentation analysis. DNA obtained from control and patient PMNL lysates from cells cultured in parallel were separated on a $2 \%$ agarose gel containing ethidium bromide. Lane $M$ contains a standard 123-bp DNA ladder. Lanes 1, 2, and 3 contain DNA from a patient with AIDS at 0,6 , and $18 \mathrm{~h}$ of culture, respectively, and lanes 4, 5, and 6 contain DNA from control PMNL at the same time points. DNA from patient PMNL show fragmentation into bands at 200-bp intervals characteristic of apoptosis already at $6 \mathrm{~h}$, while control PMNL do not exhibit DNA fragmentation until $18 \mathrm{~h}$ in culture. cytes that have been stimulated with interleukin-2 exhibit rapid apoptosis when this cytokine is withdrawn (38). A G-CSF deficiency state is plausible since the endogenous source of this cytokine is activated T cells, monocytes, and macrophages, all target cells for HIV that function abnormally in HIV patient. Administration of G-CSF to HIV-infected patients improves PMNL function, which may in part be due to inhibition of apoptosis (39).

In conclusion, PMNL apoptosis is markedly accelerated in patients with advanced HIV infection. This may explain the relative neutropenia and impaired PMNL function observed in these patients. Although circulating cytokines and inflammatory mediators could theoretically cause the increased rate of

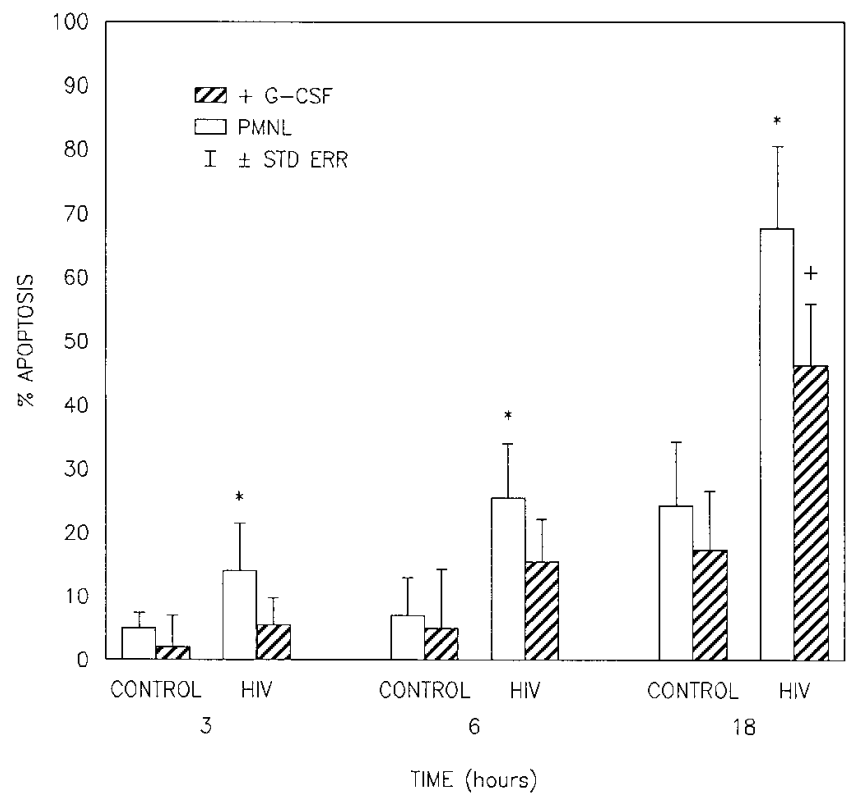

Figure 5. In vitro effect of G-CSF on PMNL apoptosis. *Indicates significant difference between the patient $(n=4)$ and control $(n=5)$ PMNL without G-CSF, $P<0.05$ by the Student's $t$ test. Incubation with $50 \mu \mathrm{g} / \mathrm{ml} \mathrm{r}$-metHuG-CSF decreased apoptosis for control and patient PMNL, although this only reached statistical significance for patient PMNL after $18 \mathrm{~h}$ of incubation (mean difference $=$ $-18.9 \pm 3.0 \%, P=0.001$, paired $t$ test). 
apoptosis, the lack of any effect of HIV sera on control PMNL in vitro argues against this. Normal PMNL development and maturation in the bone marrow may be altered in HIV infection, possibly the result of a state of relative G-CSF deficiency. Despite the fact that the accelerated apoptosis appears to be an intrinsic property of the PMNL from AIDS patients, the process is not irreversible. Incubation of PMNL with G-CSF can reverse the accelerated apoptosis in vitro. These observations may be relevant to the pathogenesis of bacterial infections and other secondary infectious complications of HIV infection, and suggest the potential for reversing apoptosis and impairment of PMNL function with cytokine therapy.

\section{Acknowledgments}

We thank Dr. Alice Pau for careful reading of this manuscript.

Filgrastim (r-met HuG-CSF) and partial support for this study were provided by Amgen, Inc. (Thousand Oaks, CA).

\section{References}

1. Wyllie, A.H., J.F.R. Kerr, and A.R. Currie. 1980. Cell death: the significance of apoptosis. Int. Rev. Cytol. 68:251-306.

2. Ellis, R.E., J.Y. Yuan, and H.R. Horvitz. 1991. Mechanisms and functions of cell death. Annu. Rev. Cell Biol. 7:663-698.

3. Savill, J.S., A.H. Wyllie, J.E. Henson, M.J. Walport, P.M. Henson, and C. Haslett. 1989. Macrophage phagocytosis of aging neutrophils in inflammation. J. Clin. Invest. 83:865-875.

4. Cohen, J.J. 1991. Programmed cell death in the immune system. Adv. Immunol. 50:55-85.

5. Takeda, Y., H. Watanabe, S. Yonehara, T. Yamashita, S. Saito, and F. Sendo. 1993. Rapid acceleration of neutrophil apoptosis by tumor necrosis factor- $\alpha$. Intl. Immunol. 5:691-694.

6. Pericle, F., J.H. Liu, J.I. Diaz, D.K. Blanchard, S. Wei, G. Forni, and J.Y. Djeu. 1994. Interleukin-2 prevention of apoptosis in human neutrophils. Eur. J. Immunol. 24:440-444.

7. Afford, S.C., J. Pongracz, R.A. Stockely, J. Crocker, and D. Burnett. 1992. The induction by human interleukin-6 of apoptosis in the promyelocytic cell line U937 and human neutrophils. J. Immunol. Chem. 267:21612-21616.

8. Colotta, F., F. Re, N. Polentarutti, S. Sozzani, and A. Mantovani. 1992. Modulation of granulocyte survival and programmed cell death by cytokines and bacterial products. Blood. 80:2012-2020.

9. Lee, A., M.K.B. Whyte, and C. Haslett. 1993. Inhibition of apoptosis and prolongation of neutrophil functional longevity by inflammatory mediators. $J$. Leukoc. Biol. 54:283-288.

10. Lazzerin, A., C. Uberti Foppa, M. Galli, A. Montovani, G. Poli, F. Franzetti, and R. Novati. 1986. Impairment of polymorphonuclear leukocyte function in patients with acquired immunodeficiency syndrome and lymphadenopathy syndrome. Clin. Exp. Immunol. 65:105-111.

11. Nielsen, H., A. Kharzami, and V. Faber. 1986. Blood monocyte and neutrophil functions in the acquired immunodeficiency syndrome. Scand. J. Immunol. 24:291-296.

12. Ellis, M., S. Gupta, S. Galant, S. Hakim, C. VandeVen, C. Toy, and M.S. Cairo. 1988. Impaired neutrophil function in patients with AIDS or AIDSrelated complex: a comprehensive evaluation. J. Infect. Dis. 158:1268-1276.

13. Murphy, P.M., H.C. Lane, A.S. Fauci, and J.I. Gallin. 1988. Impairment of neutrophil bactericidal capacity in patients with AIDS. J. Infect. Dis. 158: 627-630

14. Pitrak, D.L., P.M. Bak, P. DeMarais, R.M. Novak, and B.R. Andersen. 1993. Depressed neutrophil superoxide production in human immunodeficiency virus infection. J. Infect. Dis. 167:1406-1410.

15. Whyte, M.K.B., L.C. Meagher, J. MacDermot, and C. Haslett. 1993. Impairment of function in aging neutrophils is associated with apoptosis. J. Immunol. 150:5124-5134.

16. Ameisen, J.C., and A. Capron. 1991. Cell dysfunction and depletion in AIDS: the programmed cell death hypothesis. Immunology Today. 12:102-105.
17. Gougeon, M.L., and L. Montagnier. 1993. Apoptosis in AIDS. Science (Wash. DC). 260:1269-1270.

18. Boyum, A. 1968. Isolation of mononuclear cells and granulocytes from human peripheral blood. Scand. J. Clin. Lab. Invest. 21(Suppl 197):77-89.

19. Duke, R.C., and J.J. Cohen. 1992. Morphological and biochemical assays of apoptosis. Curr. Prot. Immunol. 1:3.17.1-3.17.16.

20. Nicoletti, I., G. Migliorati, M.C. Pagliacci, F. Grignani, and C. Riccardi. 1991. A rapid and simple method for measuring thymocyte apoptosis by propidium iodide staining and flow cytometry. J. Immunol. Methods. 139:271-279.

21. Wyllie, A.H. 1980. Glucocorticoid-induced thymocyte apoptosis is associated with endogenous endonuclease activation. Nature (Lond.). 284:555-556.

22. Bernstein, L., B.Z. Krieger, B. Novick, M.J. Sicklick, and A. Rubenstein. 1985. Bacterial infection in the acquired immunodeficiency syndrome of children. Pediatr. Infect. Dis. 4:472-475.

23. Whimbrey, E., J.M. Gold, B. Polsky, J. Dryjanski, C. Hawkins, A. Blevins, P. Brannon, T.E. Kiehn, A.E. Brown, and D. Armstrong. 1986. Bacteremia and fungemia with the acquired immunodeficiency syndrome. Ann. Intern. Med. 104:511-514.

24. Witt, D.J., D.E. Craven, and W.R. McCabe. 1987. Bacterial infections in adult patients with the acquired immunodeficiency syndrome (AIDS). Am. J. Med. 82:900-906.

25. Nichols, L., K. Balogh, and M. Silverman. 1989. Bacterial infections in the acquired immunodeficiency syndrome. Am. J. Clin. Pathol. 92:787-790.

26. Kielhofner, M., R.L. Atmar, R.J. Hamill, and D.M. Musher. 1992. Lifethreatening Pseudomonas aeruginosa infections with human immunodeficiency virus infection. Clin. Infect. Dis. 14:403-411.

27. Baldwin, G.C., N.D. Fuller, R.L. Roberts, D.D. Ho, and D.W. Golde. 1989. Granulocyte- and granulocyte-macrophage colony-stimulating factors enhance neutrophil cytotoxicity toward HIV-infected cells. Blood. 74:1673-1677.

28. Kinne, T.J., and S. Gupta. 1989. Antibody-dependent cellular cytotoxicity by polymorphonuclear leukocytes in patients with AIDS and AIDS-related complex. J. Clin. Lab. Immunol. 30:153-156.

29. Klebanoff, S.J., and R.W. Coombs. 1992. Viricidal effect of polymorphonucelar leukocytes on human immunodeficiency virus-1. J. Clin. Invest. 89: 2014-2017.

30. Mullane, K., D. Pitrak, M. Bilek, R. Novak, R. Allen, and P. Stevens. 1994. In vivo neutrophil activation and burnout in HIV infection. Clin. Res. 42: 155a (Abstr.)

31. Elbim, C., F. Bouscarat, E. Franzini, S. Collet-Martin, J. Hakin, and M.A. Gougerot-Pocidalo. 1994. Polymorphonuclear neutrophils from human immunodeficiency virus-infected patients show enhanced activation, diminished fMLP-induced L-selectin shedding, and an impaired oxidative burst after cytokine priming. Blood. 84:2759-2766.

32. Lahdevirta, J., C.P. Maury, A.M. Teppo, and H. Repo. 1988. Elevated levels of circulating cachectin/tumor necrosis factor in patients with acquired immunodeficiency syndrome. Am. J. Med. 85:289-291.

33. Brach, M.A., S. deVos, H.J. Gruss, and F. Herrmann. 1992. Prolongation of survival of human polymorphonuclear neutrophils by granulocyte-macrophage colony-stimulating factor is caused by inhibition of programmed cell death. Blood. 80:2920-2924.

34. Williams, G.T., C.A. Smith, E. Spooncer, T.M. Dexter, and D.R. Taylor. 1990. Hematopoietic colony stimulating factors promote cell survival by suppressing apoptosis. Nature (Lond.). 343:76-79.

35. Begley, C.G., A.F. Lopez, N.A. Nicols, D.J. Warren, M.A. Vadas, C.J. Sanderson, and D. Metcalf. 1986. Purified colony-stimulating factors enhance the survival of human neutrophils and eosinophils in vitro: A rapid and sensitive microassay for colony-stimulating factors. Blood. 68:162-166.

36. Watari, K., S. Asamo, N. Shirafuji, H. Kodo, K. Ozawa, F. Takakuet, and S. Kamachi. 1989. Serum granulocyte colony-stimulating factor levels in healthy volunteers and patients with various disorders as estimated by enzyme immunoassay. Blood. 73:117-122.

37. Mauss, S., H. T. Steinmetz, R. Willers, H. Jablonowski, and D. Haussinger. 1995. Low granulocyte colony-stimulating factor (G-CSF) levels in neutropenia but not in acute febrile infection in HIV seropositive individuals: a causal role for G-CSF in HIV-associated neutropenia. Program and Abstracts of the 35th ICAAC, San Francisco, 17-20 September 1995, 1250a (Abstr.).

38. Duke, R.C., and J.J. Cohen. 1986. IL-2 addiction: Withdrawal of growth factors activates a suicide program in dependent T-cells. Lymphokine Res. 5: 289-299.

39. Roilides, E., S. Mertins, J. Eddy, T.J. Walsh, P.A. Pizzo, and M. Rubin. 1990. Impairment of neutrophil chemotactic and bactericidal function in children infected with human immunodeficiency virus type 1 and partial reversal after in vitro exposure to granulocyte-macrophage colony-stimulating factor. $J$. Pediatr. 117:531-540. 